Article

\title{
Cross-Country Student Perceptions about Online Medical Education during the COVID-19 Pandemic
}

\author{
Tomoya Suzuki ${ }^{1,2, *(\mathbb{D}}$, Anju Murayama ${ }^{1, *(\mathbb{D})}$, Yasuhiro Kotera ${ }^{3}\left(\mathbb{D}\right.$, Divya Bhandari ${ }^{1}\left(\mathbb{D}\right.$, , Yuki Senoo ${ }^{1,+(\mathbb{D})}$ \\ Yuta Tani ${ }^{1,+}$, Kayo Harada ${ }^{1,+}$, Ayumu Kawamoto ${ }^{1,+}$, Satomi Sato ${ }^{1,+}$, Toyoaki Sawano ${ }^{4}$, Yasushi Miyata $5 \mathbb{D}^{\text {, }}$ \\ Masaharu Tsubokura ${ }^{1,6}{ }^{(D)}$, Tetsuya Tanimoto ${ }^{1,7}$ and Akihiko Ozaki ${ }^{1,8}$ (D)
}

Citation: Suzuki, T.; Murayama, A.; Kotera, Y.; Bhandari, D.; Senoo, Y.;

Tani, Y.; Harada, K.; Kawamoto, A.; Sato, S.; Sawano, T.; et al.

Cross-Country Student Perceptions about Online Medical Education during the COVID-19 Pandemic. Int. J. Environ. Res. Public Health 2022, 19, 2840. https://doi.org/10.3390/ ijerph19052840

Academic Editor: Paul B. Tchounwou

Received: 26 January 2022

Accepted: 25 February 2022

Published: 28 February 2022

Corrected: 30 March 2023

Publisher's Note: MDPI stays neutral with regard to jurisdictional claims in published maps and institutional affiliations.

Copyright: (C) 2022 by the authors. Licensee MDPI, Basel, Switzerland. This article is an open access article distributed under the terms and conditions of the Creative Commons Attribution (CC BY) license (https:// creativecommons.org/licenses/by/ $4.0 /)$.
1 Medical Governance Research Institute, Takanawa, Minato-ku, Tokyo 1087505, Japan; rayordeal3@gmail.com (D.B.); senooyuki0821@gmail.com (Y.S.); tyuta0430@gmail.com (Y.T.); kayoharada.0615@gmail.com (K.H.); ayumu0210604@gmail.com (A.K.); 18a1051@g.iuhw.ac.jp (S.S.); tsubokura-tky@umin.ac.jp (M.T.); tetanimot@me.com (T.T.); ozakiakihiko@gmail.com (A.O.)

2 School of Medicine, Akita University, 1-1-1 Hondo, Akita 0108543, Japan

3 School of Health Sciences, University of Nottingham, Nottingham NG7 2HA, UK; yasuhiro.kotera@nottingham.ac.uk

4 Department of Surgery, Jyoban Hospital of Tokiwa Foundation, Iwaki 9728322, Japan; toyoakisawano@gmail.com

5 Department of Primary Care and Community Health, Aichi Medical University, Nagakute 4801195, Japan; ymymiyata@gmail.com

6 Department of Radiation Health Management, Fukushima Medical University School of Medicine, Fukushima 9601247, Japan

7 Department of Internal Medicine, Navitas Clinic Kaswasaki, Kawasaki 2100007, Japan

8 Department of Breast Surgery, Jyoban Hospital of Tokiwa Foundation, Iwaki 9728322, Japan

* Correspondence: tomo1502@gmail.com (T.S.); ange21tera@gmail.com (A.M.)

$\dagger$ These authors contributed equally to this work.

\begin{abstract}
Introduction: Most educational institutions around the world have shifted from traditional face-to-face to online education amid COVID-19. This change may particularly impact medical students, whose education is heavily influenced by clinical learning experiences. Accordingly, we investigated medical students' perceptions about positive and negative aspects of online medical education in Japan and overseas during the COVID-19 pandemic. (2) Methods: In-depth online interviews were conducted among 13 Japanese medical students and five medical students from Slovakia, Norway, and Hungary. Interviews were conducted from 23rd September to 3rd October 2020 using the snowball sampling method. Questions were focused on five main areas: Q1 the type of online education; Q2 advantages and disadvantages of online education; Q3 any changes in the relationship with teachers, friends, and family; $\mathrm{Q} 4$ any opinions about further improvements in online education; and Q5 any needs for affiliation with a particular university. Then thematic analysis was conducted. (3) Results: The results of the thematic analysis revealed the following four themes that represent the positive and negative aspects of online medical education; Theme 1: Timesaving and Flexibility; Theme 2: Technical problems and lack of digital skills; Theme 3: Unstandardized teaching skills; Theme 4: Lack of experience beyond medical school lectures. (4) Conclusions: While online education was found useful in terms of saving time and creating a flexible learning environment, many important drawbacks were noted such as internet and computer problems and unstandardized teaching skills, and lack of quality assurance. In addition, experiences outside the classroom such as making relationships with faculty and friends, conducting research and participating in extracurricular activities were missed, which they normally enjoy in college life.
\end{abstract}

Keywords: undergraduate; COVID-19; pandemic; medical education; SARS-CoV-2; distance-learning 


\section{Introduction}

Clinical experience in medical education is a fundamental step for undergraduate medical students to learn practical patient care [1]. However, along with the advent of Coronavirus Disease 2019 (COVID-19), governments were forced to implement strict policy including the closure of public spaces, travel restrictions, national lockdowns, and school closure [2,3]. These restrictions were also extended to medical schools across the world, and medical students were subjected to many restrictions in their private and educational settings, such as being forced to change their normal learning environment, being isolated in their house or dormitory, etc. [4-6].

In Japan, since the first COVID-19 case was found on 16 January 2020 [7], the number of confirmed cases gradually increased, and cumulative confirmed cases reached more than 250 as of 2 March 2020 [8]. Due to pressure from the failure of the Diamond Princess [9], the Japanese government enforced a strict policy to close schools as early as 2 March 2020, to prevent an outbreak. Subsequently, with the increase in COVID-19 cases, Japanese medical students were also affected by the cancellation of clinical training and the shift to online education [10]. Due to the need to provide online lectures in almost all schools, the Japanese government established an exception to permit all educational institutions to use copyrighted works in online lectures free of charge only for the fiscal year 2020. Owing to this act, most educational institutions, including medical schools, shifted from traditional face-to-face education to online education, albeit with a few obstacles [5,11,12]. The number of people infected with COVID-19 was high not only in Japan; European countries also had high levels of infection [13]. Accordingly, the nationwide lockdown restrictions were implemented to control the spread of disease in Europe. Medical education in Europe has also been affected by the halting of lectures and clinical training, resulting in a sudden shift to online teaching [14-16].

Given that several studies have shown that the novel learning methods are equally or more effective than the traditional offline learning in ordinary settings [17-21], in an emergency setting such as the COVID-19 pandemic, online education potentially could be helpful and more effective to continue education in medical schools. However, the first-hand experience of medical students with regard to online education under such emergency conditions has yet to be evaluated. Accordingly, this study chiefly aimed to elucidate and discuss the impact of online learning among medical students in Japan during the COVID-19 pandemic. We included a few medical students from European countries with incomes as high as those from Japan because we intended to evaluate the results in Japan relatively [22].

\section{Methods}

\subsection{Study Populations}

Participants were recruited using snowball and purposive sampling methods as we wanted to recruit students who could afford to take part in this study, i.e., those whom we judged to be mentally well (not severely distressed by the shift to online learning). Data saturation was judged to be reached by all the authors: the collected data meaningfully responded to the research questions, and no further interviews would yield any additional insights to the study aim. We recruited participants from interviewers' acquaintances and participants introduced the next one to us based on their acquaintances. We sent invitations to candidates using email and social networking services including LINE (LINE Corporation, Tokyo, Japan), Messenger (Facebook, Inc., Menlo Park, CA, USA), and Instagram (Facebook, Inc., Menlo Park, CA, USA). The study protocol was also made available to some participants who requested more detailed information. A total of 18 participants were included in the study. We stopped the interview (after obtaining a response from the 18th participant) once the data was found saturated since more interviews would not yield any new findings. 


\subsection{Interview Procedures and Content}

Semi-structured interviews were conducted with medical students in Japan and overseas using web conferencing software ZOOM (version 5.4.6, Zoom Video Communications, Inc., Menlo Park, CA, USA). We used semi-structured interviews instead of structured ones. Using semi-structured questions as the basis, we allowed the topic to change, developed further, and summarized the items that the authors consider important and relevant since no similar study has been conducted in COVID-19 pandemic in the previous literature. The interviews were recorded. We employed a video interview method for several reasons such as international participant recruitment, adherence to physical distancing, and effectiveness for discussion $[23,24]$.

There were six interviewers who are all Japanese medical students. All of them received two hours of training on how to effectively collect qualitative data from experts. Each interview was conducted by two interviewers to limit biases in questioning and interpretation. For each participant, two interviewers were chosen in such a way that the participant did not know anything about the interviewers, apart from that they were medical students. Before the interviews, we obtained the consent of all the participants to record their interviews for the analysis, and all interviews were recorded.

The interview guide was developed based on our study interest and previous studies $[5,17,19,20,25]$. The interviewers were guided by the following five open-ended questions structured around the participants' experience, mainly with online education during the COVID-19 pandemic: (Q1) a type of online education, which participants had received during the COVID-19 pandemic; (Q2) advantages and disadvantages of online education, which participants had experienced; (Q3) changes in the relationship with teachers, peers, friends, and family; (Q4) opinions on further improvement of online education, and (Q5) the necessity to belong to a particular university when education can be received online without belonging. Along with open-ended questions, participants were also asked for demographic information. To ensure the accuracy of transcribing, all participants received the transcript and confirmed the accuracy.

\subsection{Interviewees}

We sent the survey invitation and 21 participants agreed to be interviewed. In total, 18 participants finally completed an online interview via ZOOM: three did not complete due to system errors. Since data saturation was observed in the 18 th interview, we did not feel the need to follow up with those three participants again. The interviews were conducted from 23 September to 3 October 2020.

\subsection{Basic Characteristics}

Participants were asked sex, nationality, country of university, age, grade, living status, academic confidence, a common place to study, study mode (whether they preferred studying alone, in a group, or both), previous experience of online learning, confidence in using the internet in general, and internet literacy (Table 1).

\subsection{Data Analysis}

Thematic analysis was conducted. Following the methods designed by Baraun and Clarke [26], after familiarization, codes were generated, which were then categorized thematically. Coherence and distinctiveness of themes were reviewed by A.O., Y.K., Y.S., and A.M.

\subsection{Ethics Approval}

The Institutional Review Board of Medical Governance Research Institute granted ethics approval of this study (MG2020-09-20200904) on 4 September 2020, adhering to the guidelines established by the Ministry of Health Labor and Welfare (MHLW) and The Ministry of Education, Culture, Sports, Science, and Technology (MEXT) in Japan [27]. 
Table 1. Basic characteristic.

\begin{tabular}{|c|c|c|c|c|c|c|c|c|c|c|c|c|}
\hline Sex/No & $\begin{array}{l}\text { Native } \\
\text { Place }\end{array}$ & $\begin{array}{l}\text { Country of } \\
\text { University }\end{array}$ & Age & Grade & $\begin{array}{c}\text { Interview } \\
\text { Duration (min) }\end{array}$ & $\begin{array}{l}\text { Living } \\
\text { Status }\end{array}$ & $\begin{array}{l}\text { Academic } \\
\text { Confidence }\end{array}$ & $\begin{array}{l}\text { Place to } \\
\text { Study }\end{array}$ & $\begin{array}{l}\text { Study } \\
\text { Mode }\end{array}$ & $\begin{array}{l}\text { Experience of } \\
\text { Online Learning }\end{array}$ & $\begin{array}{c}\text { Internet } \\
\text { Confidence }\end{array}$ & $\begin{array}{l}\text { Internet } \\
\text { Literacy }\end{array}$ \\
\hline F1 & PNS & Slovakia & 30 & 6 & 46 & Alone & Good & Library & Alone & Yes & Poor & Yes \\
\hline F2 & Germany & Slovakia & 26 & 6 & 34 & Alone & Good & Library & Group & Yes & Poor & Yes \\
\hline M4 & Japan & Japan & 24 & 6 & 20 & Alone & Poor & $\begin{array}{c}\text { Home, } \\
\text { University }\end{array}$ & Both & No & Poor & Yes \\
\hline M5 & Japan & Japan & 23 & 6 & 45 & Alone & Good & Home & Alone & Yes & Good & Yes \\
\hline F6 & China & Hungary & 25 & 4 & 30 & Alone & Moderate & $\begin{array}{l}\text { Library } \\
\text { Home }\end{array}$ & Group & Yes & Poor & Yes \\
\hline M7 & Japan & Japan & 23 & 4 & 30 & Alone & Good & Home & Alone & No & Poor & Yes \\
\hline F8 & Japan & Slovakia & PNS & 4 & 51 & Alone & Poor & Home & Group & No & Poor & Yes \\
\hline F9 & Japan & Japan & 23 & 4 & 31 & Alone & Good & Home & Both & No & Poor & Yes \\
\hline F10 & Japan & Japan & 23 & 4 & 45 & Alone & Good & Home & Alone & Yes & Good & Yes \\
\hline F11 & Japan & Japan & 22 & 3 & 27 & Alone & Good & Library & Both & No & Poor & Yes \\
\hline M12 & Japan & Japan & 21 & 3 & 30 & Alone & Good & Library & Alone & No & Poor & No \\
\hline M13 & Japan & Japan & 21 & 3 & 47 & Alone & Good & Library & Group & No & Poor & Yes \\
\hline $\mathrm{F} 14$ & Japan & Japan & 20 & 3 & 33 & Alone & Good & Home & Alone & No & Poor & Yes \\
\hline M15 & Japan & Japan & 20 & 3 & 30 & Alone & Poor & Café & Alone & No & Poor & Yes \\
\hline F18 & Japan & Japan & 19 & 1 & 46 & Family & Good & Outside & Alone & Yes & Poor & Yes \\
\hline
\end{tabular}




\section{Results}

The mean interview time was $38 \mathrm{~min}$ (Min $27 \mathrm{~min}$, Max $59 \mathrm{~min}$, SD $18 \mathrm{~min}$ ). The study participants were six males (33\%) and 12 females $(67 \%)$, and a median of 23 years old (IQR: 20-24). In total, 13 participants were from nine different medical schools in Japan, and the remaining five were from three in Slovakia, two in Norway and Hungary. Table 1 summarized the detailed characteristics of the participants and the interviews.

\section{Thematic Analysis}

Participants' responses to the five questions were coded and themed.

\subsection{Theme 1: Timesaving and Flexibility}

Participants reported that online learning helped them to save a lot of time. This allowed them more time for other activities such as saving their commuting time or spending more time sleeping. In addition, some universities provided an environment in which students can watch online classes at any time by downloading recordings of real-time classes on their online platform. It gives medical students time flexibility in their study pace.

Participant No.13: "As I don't have to commute to school, so I can sleep longer. I don't have to go to and from school, so I can do whatever I want." (Q2)

Participant No.10: "It takes a long time for students in rural areas to commute to school. ... I can use that time to study for my exam." (Q2)

Participant No.3: "I have lectures at the university hospital, so the classrooms are different every time. In online learning, I don't have to spend time traveling and searching." (Q2)

Participant No.2: "The advantage of recorded online classes is that they can be played back, rewound, and watched over and over again." (Q2)

Participant No.8: "With online, we can study at our own pace. I don't have to go to the university at a certain time." $(\mathrm{Q} 2)$

\subsection{Theme 2: Technical Problems and Lack of Digital Skills}

Participants also reported the disadvantages of online learning such as technical problems. More than half of the participants reported these as a serious issue and that they had either encountered or witnessed some technical problems with accessing the course materials and tutoring sessions.

Participant No.6: "Some students even failed an exam because of technical errors; however, it wasn't their fault. It was partly due to a lack of proper management by the university."

Participant No.12: "There were a lot of problems. For example, the lecturer's microphone wasn't on, but he just kept talking without realizing it." (Q1)

Participant No.16: "I had trouble getting into ZOOM." (Q2)

Participant No.2: "The unstable Wi-Fi at my home put me in a tough situation. Because of it, my test was rescheduled." (Q1)

Technical problems can be diverse, including system errors, the Wi-Fi setting at home, and the use of visual/audio devices. Some of these problems are related to the digital skills of the students and staff. Regardless of how good an online learning environment is, if it's not used properly, students may encounter multiple problems.

\subsection{Theme 3: Unstandardized Teaching Skills}

Many students observed great variation in the online teaching skills of their lecturers. 
Participant No.8: “There were not so many well-designed classes. Many teachers were unfamiliar with online teaching, and only a few of them were making well-planned online classes." (Q1)

Participant No.9: "The quality of the classes varied greatly from subject to subject, and I felt that regular face-to-face classes were more consistent and better." (Q2)

Participant No.13: "Sometimes, online conversations were hard to understand. I prefer textbooks to facilitate learning." (Q3)

While some lecturers were able to adjust to online teaching, others had trouble adjusting to a new method of teaching. During the COVID-19 pandemic, lecturers were forced to teach online even if they were unprepared for it, highlighting the lack of training they had in online teaching.

\subsection{Theme 4: Lack of Experience beyond Medical Schools Lectures}

Some students reported that they were not able to connect with faculty and friends due to restrictions imposed on them from going to the universities and hospitals as well as participating in extracurricular activities. Many participants commented that online classes made it difficult for both teachers and students to ask questions and to remember each other's faces and names, which created a great distance from lecturers.

Participant No.3: "Professors didn't see us during the lecture because we turned off the camera in a big group."

Participant No.11: "In online classes, faculty members no longer randomly call students to ask questions during class or have a small talk with students before or after class. As a result, the distance between the lecturers and students has increased, and I can't match the face and name of some of the lecturers anymore."

Participant No.9: "As I couldn't see my friends in the remote class, I wasn't aware how they were preparing for the exam." (Q2)

Participant No.3: "Before the summer I was quite lonely. It was hard to stay motivated to study since I wasn't seeing my friends." (Q3)

Students felt less connected with their peers, which led to a sense of loneliness and decreased motivation to study. Moreover, their inability to exchange information about the class and their progress also hindered them from staying motivated.

As for the benefits of belonging to a particular university (Question 5), many students mentioned the benefit of having a sense of belonging through relationships with friends and faculty through research and extracurricular activities.

Participant No.2: "The feeling of being in the part of group is one of the most important things. You go there every day and there are people to talk with friends." (Q5)

Participant No.16: "If you want to be involved in cutting-edge research, I think it is worthwhile to belong to a particular university [that is strong in that research area], but I don't think the university classes themselves have any value." (Q5)

Although these students mentioned the advantages of belongingness to a particular university, these benefits such as participating in extracurricular activities and building relationship with friends and faculty were lessened in online education in the COVID-19 pandemic.

\section{Discussion}

This qualitative study evaluated online medical education in Japan and Europe from the students' perspectives. Our thematic analysis identified four themes, illustrating the positive and negative aspects of online medical education during the COVID-19.

One notable finding was that online learning saved time and provide flexibility to the students (Theme 1). The finding of our study is consistent with pre-COVID-19 online 
education studies. For example, a previous study in the United Kingdom reported that online learning saves students' commuting time, allows students to study at their own pace, and gives wider access to learning materials as advantages [28]. Although this advantage has been noted in another previous study [29], our data suggests that this advantage was achieved even in the sudden enforced and unprepared delivery of online learning in the COVID-19 pandemic.

While participants emphasized time-saving and time-flexibility as the biggest advantages, it is important to note that this may also imply an increased need for self-management. For example, students who usually maintained their academic motivation by meeting their teachers and friends in person (Theme 4) complained of decreased motivation to learn along with mental health difficulties. Previous studies in the U.S. and Japan have also reported an increase in the number of students suffering from psychological symptoms during the pandemic $[25,30]$. To support the learning of these students, the university's staffs and wellbeing services need to be mindful of students' mental health difficulties such as low motivation and loneliness. For example, mental health interventions such as social support to augment resilience and hope were reported helpful to online students [31]. These interventions need to be implemented and evaluated, in order to protect students from mental health difficulties.

In addition, a previous study has highlighted that living far from home was one of the risk factors for mental illness among students [30]. Considering such students who struggled with self-management and are at risk of mental illness, online education may require mental health support. During the COVID-19 pandemic, however, many students returned to their hometown or other socially supportive environments and studied from there, which might have mitigated the mental health difficulties associated with online learning. In line with the positive opinion of saving commuting time (Theme 1) and a negative association between commuting time to school/work and stress [28,32], we believe that time-flexibility such as saving commuting time and the previous report can be regarded as positive opinions that support the active introduction of online classes.

The negative themes include technical problems and a lack of digital skills (Theme 2), unstandardized teaching skills (Theme 3), loss of experiences other than lectures (Theme 4), which were also generally consistent with previous studies about online medical education before and during the COVID-19 pandemic [33,34]. The major difference between the preCOVID-19 studies and the present study is that online medical education in the COVID-19 pandemic was introduced without sufficient preparation, leading to a great burden for many universities, faculty members, and students. This lack of preparation can somewhat contextualize these negative themes in this study. For example, some students reported that the quality of online education was dependent on the faculty members' online teaching skills (Theme 3). Universities and faculty members, who had been active in online education during the pre-COVID-19 time have smoothly provided high-quality online education even in the COVID-19 pandemic [25]. Furthermore, sufficient training and preparation including the development of digital skills for online education can positively affect student satisfaction $[35,36]$. Along with those hard skills in online teaching, soft skills such as active interaction or an informal chat with students, in the online platform need to be developed [37], considering the comments such as "difficulty in asking questions", "faculty members not remembering students' faces", and "no interaction during class" (Theme 4). These findings are in line with the social presence theory of online education, where the faculty's presence in the curriculum can impact students' learning experience [33,38].

In this respect, we believe that the social presence theory can be applied to medical education during the COVID-19 pandemic. It is difficult to bring about a sense of belongingness and community in online learning, which often leads to a feeling of alienation in students and lower learning outcomes. Indeed, the students who participated in this study accorded with it (Theme 4). Studies reported that emotional responses including politeness, humor, cooperative responses, and cohesiveness have been proposed as solutions, creating a stronger sense of community online [39]. We suggest that these attempts should be incor- 
porated into online medical education during and possibly after the COVID-19 pandemic to increase student learning experience, achievement, and the meaning of belongingness in a particular university.

Lastly, standardized teaching skills (Theme 3) can be another major solution to support students' learning and wellbeing. For Theme 3: Unstandardized teaching skills, two possible solutions can be suggested based on our findings. The first is the need to create and distribute systematized materials, in which the order of teaching items is standardized (e.g., from diseases or from anatomy). Furthermore, these materials need to be prepared in the written format as well as the spoken one in online classes, which can address the auditory difficulties as reported by No. 13 in Theme 3: "Sometimes it is difficult to hear the teacher's voice and words online." This is often attributed to Theme 2: "Technical problems and digital skills." Even when such problems occur, students can learn on their own if there are materials that describe the contents of the class. Second, faculty members should have the opportunity to contact students individually via email or other means to answer questions. According to our result in Theme 4, Participant No. 11 commented that students and faculty no longer talked to each other before or after class. Online classes are less engaged, especially with faculty members. As medical classes are relatively informationintensive, it is also important for online medical education to provide individualized communication before and after class.

Finally, there was no significant difference in the results of the survey on online medical education between European medical students and Japanese medical students. We consider that there could be three plausible explanations. First, medical training is largely the same between Europe and Japan. Japan originally introduced the modern concept of medicine from European countries such as the Netherlands and Germany in the Edo and Meiji Era more than 100 years ago. Second, the developmental level of the two regions is roughly the same as shown in the gross domestic product per capita of two regions [40]. Lastly, we could only include four participants from Europe, which might have limited the ability to detect potential differences between the two education systems. Indeed, this is a substantial limitation of this study and is later covered in the limitation section as well.

\section{Limitations}

First, the sample size for students from Europe was low. A larger and more balanced sample would have made our findings more generalizable. Second, the interview questions have the same structure and guidelines, but the duration of the interview was not constant. This might suggest variance in the depth of the participant responses.

\section{Conclusions}

The novelty of our study lies in positive aspects such as timesaving and flexibility in the learning environment, and negative ones such as internet condition, quality of online lectures and lack of experience beyond medical school lectures (e.g., extracurricular activities). Findings from this study will provide foundational data to improve the quality of online medical education.

Author Contributions: Conceptualization, T.S. (Tomoya Suzuki), A.M., Y.K., Y.S., Y.T., K.H., T.S (Toyoaki Sawano), Y.M., M.T., and A.O.; methodology, Y.K.; formal analysis, T.S. (Tomoya Suzuki); investigation, A.M., Y.S., Y.T., K.H., A.K., and S.S.; data curation, A.M.; writing-original draft preparation, T.S. (Tomoya Suzuki), A.M., and A.O.; writing-review and editing, T.S. (Tomoya Suzuki), A.M., Y.K., D.B., and A.O.; supervision, T.S. (Toyoaki Sawano), Y.M., M.T., T.T., and A.O.; and project administration, Y.K., T.T. and A.O. All authors have read and agreed to the published version of the manuscript.

Funding: This research received no external funding.

Institutional Review Board Statement: The study was conducted according to the guidelines of the Declaration of Helsinki, and approved by the Institutional Review Board of Medical Governance Research Institute (MG2020-09-20200904 on 4 September 2020). 
Informed Consent Statement: Informed consent was obtained from all subjects involved in the study.

Data Availability Statement: The datasets not available due to ethical restrictions.

Acknowledgments: We would like to thank Masahiro Kami for his constructive opinions.

Conflicts of Interest: Akihiko Ozaki receives the personal fees from MNES Inc., outside the submitted work. The other authors declare no conflict of interest.

\section{References}

1. Hearn, J.; Dewji, M.; Stocker, C.; Simons, G. Patient-centered medical education: A proposed definition. Med. Teach. 2019, 41, 934-938. [CrossRef] [PubMed]

2. Flaxman, S.; Mishra, S.; Gandy, A.; Juliette Unwin, H.T.; Mellan, T.A.; Coupland, H.; Whittaker, C.; Zhu, H.; Berah, T.; Eaton, J.W.; et al. Estimating the effects of non-pharmaceutical interventions on COVID-19 in Europe Mélodie Monod, Imperial College COVID-19 Response Team. Nature 2020, 584, 257-261. [CrossRef] [PubMed]

3. Hens, N.; Vranck, P.; Molenberghs, G. The COVID-19 epidemic, its mortality, and the role of non-pharmaceutical interventions . Eur. Heart J. Acute Cardiovasc. Care 2020, 9, 204-208. [CrossRef]

4. Wang, S.; Dai, M. Status and situation of postgraduate medical students in China under the influence of COVID-19. Postgrad. Med. J. 2020, 96, 728-730. [CrossRef]

5. Arima, M.; Takamiya, Y.; Furuta, A.; Siriratsivawong, K.; Tsuchiya, S.; Izumi, M. Factors associated with the mental health status of medical students during the COVID-19 pandemic: A cross-sectional study in Japan. BMJ Open 2020, 10, e043728. [CrossRef] [PubMed]

6. Liang, Z.C.; Ooi, S.B.S.; Wang, W. Pandemics and Their Impact on Medical Training: Lessons from Singapore. Acad. Med. 2020, 95, 1359-1361. [CrossRef] [PubMed]

7. Kyodo News+ Abe Declares Coronavirus Emergency over in Japan. Available online: https://english.kyodonews.net/news/20 20/05/a1f00cf165ae-japan-poised-to-end-state-of-emergency-over-coronavirus-crisis.html (accessed on 7 July 2021).

8. Dong, E.; Du, H.; Gardner, L. An interactive web-based dashboard to track COVID-19 in real time. Lancet Infect. Dis. 2020, 20, 533-534. [CrossRef]

9. Sawano, T.; Ozaki, A.; Rodriguez-Morales, A.J.; Tanimoto, T.; Sah, R. Limiting spread of COVID-19 from cruise ships: Lessons to be learnt from Japan. QJM Int. J. Med. 2020, 113, 309-310. [CrossRef]

10. Global Monitoring of School Closures Caused by COVID-19 Pandemic-Dashboards-COVID-19 Response. Available online: https:/ / covid19.uis.unesco.org/global-monitoring-school-closures-covid19/ (accessed on 25 January 2022).

11. Nishimura, Y.; Ochi, K.; Tokumasu, K.; Obika, M.; Hagiya, H.; Kataoka, H.; Otsuka, F. Impact of the COVID-19 Pandemic on the Psychological Distress of Medical Students in Japan: Cross-sectional Survey Study. J. Med. Internet Res. 2021, 23, e25232. [CrossRef]

12. All-Japan Federation of Student Self-Government Associations Giving Medical Students a Voice! A Survey of Perceptions and Lifestyles in the Corona Era. Available online: https://www.igakuren.jp/cms/wp-content/uploads/2021/04/\%E3\%80\%90 \%E5\%AE \%8C \%E6\%88\%90\%E7\%89\%88\%E3\%80\%91\%E3\%80\%8C\%E5\%8C\%BB\%E5\%AD\%A6\%E7\%94\%9F\%E3\%81\%AE\%E5 \%A3\%B0\%E3\%82\%92\%E5\%B1\%8A\%E3\%81\%91\%E3\%82\%8B\%EF\%BC\%81\%E3\%82\%B3\%E3\%83\%AD \%E3\%83\%8A\%E6\%99\% 82\%E4\%BB\%A3\%E3\%81\%AE\%E6\%84\%8F\%E8\%AD\%98\%E3\%81\%A8\%E7\%94\%9F\%E6\%B4\%BB\%E3\%81\%AE\%E5\%AE\%9F\% E6\%85\%8B\%E8\%AA\%BF\%E6\%9F\%BB\%E3\%80\%8D\%E6\%9C\%80\%E7\%B5\%82\%E5\%A0\%B1\%E5\%91\%8A\%E6\%9B\%B8.pdf? fbclid=IwAR05oyhQOYF9p9Lw2eudBG_xxajik5fDtztgGCZGMZup2wcPfxYTY-_NFf0 (accessed on 25 January 2022).

13. Coronavirus Disease 2019 (COVID-19) Situation Report-94 Highlights. Available online: https://apps.who.int/iris/handle/1066 5/331865 (accessed on 20 January 2022).

14. Daumiller, M.; Rinas, R.; Hein, J.; Janke, S.; Dickhäuser, O.; Dresel, M. Shifting from face-to-face to online teaching during COVID-19: The role of university faculty achievement goals for attitudes towards this sudden change, and their relevance for burnout/engagement and student evaluations of teaching quality. Comput. Hum. Behav. 2021, 118, 106677. [CrossRef]

15. Luciano, F.; Cenacchi, V.; Vegro, V.; Pavei, G. COVID-19 lockdown: Physical activity, sedentary behaviour and sleep in Italian medicine students. Eur. J. Sport Sci. 2021, 21, 1459-1468. [CrossRef] [PubMed]

16. Sandhu, P.; de Wolf, M. The impact of COVID-19 on the undergraduate medical curriculum. Med. Educ. Online 2020, 25, 1764740. [CrossRef] [PubMed]

17. Pei, L.; $\mathrm{Wu}, \mathrm{H}$. Does online learning work better than offline learning in undergraduate medical education? A systematic review and meta-analysis. Med. Educ. Online 2019, 24, 1666538. [CrossRef] [PubMed]

18. Subramanian, A.; Timberlake, M.; Mittakanti, H.; Lara, M.; Brandt, M.L. Novel educational approach for medical students: Improved retention rates using interactive medical software compared with traditional lecture-based format. J. Surg. Educ. 2012, 69, 253-256. [CrossRef] [PubMed]

19. Assadi, T.; Mofidi, M.; Rezai, M.; Hafezimoghadam, P.; Maghsoudi, M.; Mosaddegh, R.; Aghdam, H.; Mofidi, M.; Rezai, M.; Hafezimoghadam, P.; et al. The Comparison between two Methods of Basic Life Support Instruction: Video Self-Instruction versus Traditional Method. Hong Kong J. Emerg. Med. 2017, 22, 291-296. [CrossRef] 
20. Guetterman, T.C.; Sakakibara, R.; Baireddy, S.; Kron, F.W.; Scerbo, M.W.; Cleary, J.F.; Fetters, M.D. Medical Students' Experiences and Outcomes Using a Virtual Human Simulation to Improve Communication Skills: Mixed Methods Study. J. Med. Internet Res. 2019, 21, e15459. [CrossRef] [PubMed]

21. Tang, B.; Coret, A.; Qureshi, A.; Barron, H.; Ayala, A.P.; Law, M. Online Lectures in Undergraduate Medical Education: Scoping Review. JMIR Med. Educ. 2018, 4, e9091. [CrossRef]

22. European Commission, Directorate-General for Economic and Financial Affairs. European Economic Forecast: Autumn 2021 (Interim); European Commission: Brussels, Belgium, 2021. [CrossRef]

23. Novick, G. Is there a bias against telephone interviews in qualitative research? Res. Nurs. Health 2008, 31, 391-398. [CrossRef]

24. Heath, J.; Williamson, H.; Williams, L.; Harcourt, D. "It's just more personal”: Using multiple methods of qualitative data collection to facilitate participation in research focusing on sensitive subjects. Appl. Nurs. Res. 2018, 43, 30-35. [CrossRef]

25. Son, C.; Hegde, S.; Smith, A.; Wang, X.; Sasangohar, F. Effects of COVID-19 on College Students' Mental Health in the United States: Interview Survey Study. J. Med. Internet Res. 2020, 22, e21279. [CrossRef]

26. Braun, V.; Clarke, V. Using thematic analysis in psychology. Qual. Res. Psychol. 2006, 3, 77-101. [CrossRef]

27. Ethical Guidelines for Medical and Biological Research Involving Human Subjects. Available online: https://www.mhlw.go.jp/ file/06-Seisakujouhou-10600000-Daijinkanboukouseikagakuka/0000080278.pdf (accessed on 20 January 2022).

28. Dost, S.; Hossain, A.; Shehab, M.; Abdelwahed, A.; Al-Nusair, L. Perceptions of medical students towards online teaching during the COVID-19 pandemic: A national cross-sectional survey of 2721 UK medical students. BMJ Open 2020, 10, e042378. [CrossRef] [PubMed]

29. Kumar, D. Pros and Cons of Online Education. 2010. Available online: https://www.ies.ncsu.edu/resources/white-papers/prosand-cons-of-online-education/ (accessed on 20 January 2022).

30. Nomura, K.; Minamizono, S.; Maeda, E.; Kim, R.; Iwata, T.; Hirayama, J.; Ono, K.; Fushimi, M.; Goto, T.; Mishima, K.; et al. Crosssectional survey of depressive symptoms and suicide-related ideation at a Japanese national university during the COVID-19 stay-home order. Environ. Health Prev. Med. 2021, 26, 1-9. [CrossRef]

31. Barratt, J.M.; Duran, F. Does psychological capital and social support impact engagement and burnout in online distance learning students? Internet High. Educ. 2021, 51, 100821. [CrossRef]

32. Hill, M.R.; Goicochea, S.; Merlo, L.J. In their own words: Stressors facing medical students in the millennial generation. Med. Educ. Online 2018, 23, 1530558. [CrossRef]

33. Tuma, F.; Nassar, A.K.; Kamel, M.K.; Knowlton, L.M.; Jawad, N.K. Students and faculty perception of distance medical education outcomes in resource-constrained system during COVID-19 pandemic. A cross-sectional study. Ann. Med. Surg. 2021, 62, 377-382. [CrossRef]

34. Mukhtar, K.; Javed, K.; Arooj, M.; Sethi, A. Advantages, Limitations and Recommendations for online learning during COVID-19 pandemic era. Pak. J. Med. Sci. 2020, 36, S27. [CrossRef]

35. Coman, C.; Tîru, L.G.; Meseșan-Schmitz, L.; Stanciu, C.; Bularca, M.C. Online Teaching and Learning in Higher Education during the Coronavirus Pandemic: Students' Perspective. Sustainability 2020, 12, 10367. [CrossRef]

36. Mpungose, C.B. Emergent transition from face-to-face to online learning in a South African University in the context of the Coronavirus pandemic. Humanit. Soc. Sci. Commun. 2020, 7, 1-9. [CrossRef]

37. Kotera, Y.; Cockerill, V.; Green, P.; Hutchinson, L.; Shaw, P.; Bowskill, N. Towards another kind of borderlessness: Online students with disabilities. Distance Educ. 2019, 40, 170-186. [CrossRef]

38. Garrison, D.R. E-Learning in the 21st Century: A Framework for Research and Practice, 2nd ed.; Taylor \& Francis: Abingdon, UK, 2011; pp. 1-166. [CrossRef]

39. Chmiel, A.; Sienkiewicz, J.; Thelwall, M.; Paltoglou, G.; Buckley, K.; Kappas, A.; Hołyst, J.A. Collective Emotions Online and Their Influence on Community Life. PLoS ONE 2011, 6, e22207. [CrossRef] [PubMed]

40. GDP per Capita (Current US\$)-Japan I Data. Available online: https://data.worldbank.org/indicator/NY.GDP.PCAP.CD? locations=JP\&most_recent_year_desc=false (accessed on 25 January 2022). 